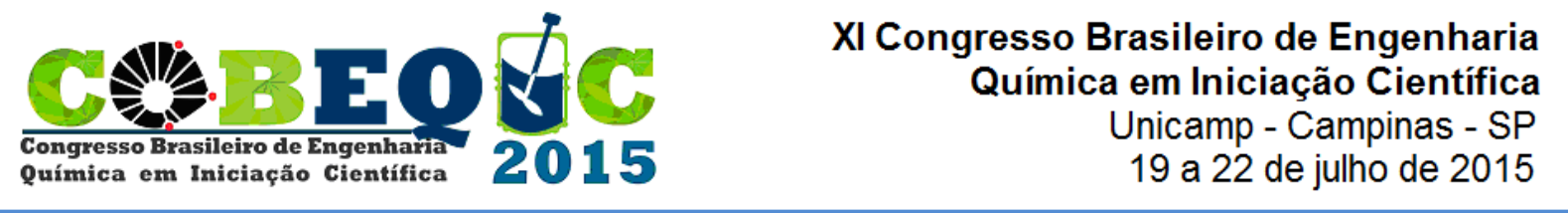

\title{
DETERMINAÇÃO DA DENSIDADE DE CORRENTE LIMITE E AVALIAÇÃO DA INFLUÊNCIA DA VAZÃO NA UNIDADE DE ELETRODIÁLISE
}

\author{
C. S. L. dos SANTOS ${ }^{1}$, M. V. FIRMINO ${ }^{1}$, M. M. de RESENDE ${ }^{1}$ e V. L. CARDOSO ${ }^{1}$. \\ ${ }^{1}$ Universidade Federal de Uberlândia, Faculdade de Engenharia Química \\ E-mail para contato: mresende@feq.ufu.br
}

\begin{abstract}
RESUMO - A eletrodiálise é um processo de separação que utilizada membranas e potencial elétrico para remoção de íons de efluentes contaminados e tem se destacado devido às inúmeras vantagens frente às outras técnicas como, por exemplo, a não precipitação dos íons na forma de hidróxidos metálicos. Mesmo assim, um parâmetro conhecido por densidade de corrente limite merece bastante atenção por reduzir consideravelmente a eficiência do processo através de um fenômeno conhecido por polarização por concentração das membranas. Este trabalho teve por objetivo determinar a máxima corrente a ser utilizada na unidade sem que ocorra a polarização das membranas de troca iônica; bem como avaliar a influência das vazões de eletrólito, solução diluída e solução concentrada na eficiência do processo para a remoção do íon $\mathrm{Cr}_{2} \mathrm{O}_{7}{ }^{-2}$. Foi utilizado uma unidade experimental com três tanques de armazenagem e uma a célula eletrolítica PCCell ED 64002 com dois compartimentos. As soluções foram água destilada, solução de dicromato de potássio em várias concentrações e solução $\mathrm{Na}_{2} \mathrm{SO}_{4} 0,25 \mathrm{M}$. De acordo com os resultados encontrados, a máxima densidade da corrente limite a ser utilizada é aproximadamente $0,03 \mathrm{~A}$ e as melhores vazões para operação da unidade é 20-60-60 e 60-60-60 L/h, considerando uma margem de segurança de $25 \%$ para menos.
\end{abstract}

\section{INTRODUÇÃO}

A escassez de água e a necessidade cada vez maior de reutilização da mesma, acopladas com normas e leis ambientais cada vez mais rígidas, têm despertado o interesse mundial em pesquisas que busquem como objetivo principal tratar resíduos industriais para que os mesmos possam ser descartados no meio ambiente de acordo com a legislação ambiental. A indústria de couro é uma das que possui um elevado potencial poluidor devido ao grande uso do cromo, o qual se apresenta em grandes quantidades no resíduo do processo. Esse metal também é empregado em vários setores produtivos como, por exemplo, em siderúrgicas, metalúrgicas, indústrias têxteis, de galvanoplastia e tintas, usinas nucleares, preservação de madeira, dentre outros.

Sabe-se que os tratamentos de águas geradas em processos industriais são complexos, pois é necessário que eles sejam específicos e que ocorram, preferencialmente, próximos aos pontos de contaminação. Surge então uma demanda por novas tecnologias limpas objetivando aperfeiçoar a descontaminação de efluentes como, por exemplo, a eletrodiálise. 


\subsection{Eletrodiálise}

De acordo com Galuchi (2010), a eletrodiálise é um processo de separação que utiliza membranas e potencial elétrico. A unidade elementar dessa é o par de células que consiste na justaposição de uma membrana catiônica, um espaçador da alimentação, uma membrana aniônica e um espaçador de água. As membranas trocadoras de íons são compostas por uma matriz polimérica contendo íons fixados em sua estrutura (cargas negativas nas catiônicas e positivas nas aniônicas) e geralmente são planas.

.No equipamento, os pares de células são colocados um após o outro, como em uma pilha, sendo a ordem de colocação dos pares dentro do empilhamento que permite a separação dos íons da solução diluída para a solução concentrada. Os eletrodos são colocados nas extremidades do empilhamento. Nos compartimentos dos eletrodos circula uma solução salina (eletrólito), mas a mesma não se mistura com as outras duas. Um esquema simplificado é apresentado na Figura 1.

Figura 1-Representação do processo de eletrodiálise. (Amorim et.al, 2005).

Quando um campo elétrico é aplicado entre os eletrodos, o ânodo fica com carga positiva e o cátodo fica com carga negativa. O campo elétrico aplicado origina a migração dos íons positivos (cátions) para o cátodo e dos íons negativos (ânions) para o ânodo. Durante o processo os ânions passam pela membrana aniônica, mas são barrados pela membrana catiônica. Um comportamento semelhante, porém inverso, acontece com os cátions $\mathrm{A}$ quantidade de carga elétrica transportada pelos íons é proporcional à concentração Solução dos eletrodos de cada espécie na solução e nas membranas.

Apesar da eletrodiálise ter significativas vantagens sobre outras técnicas de remoção de contaminantes, a polarização por concentração das membranas de troca iônica pode reduzir significativamente a eficiência desse processo. Esse fenômeno ocorre devido à escassez de íons na superfície da membrana, o que provoca um aumento brusco na queda de tensão na região da camada limite. A densidade de corrente limite ( $\left.i_{\lim }\right)$ é o parâmetro utilizado para o monitoramento dos íons na superfície da membrana, pois ela ocorre quando a concentração de íons na superfície das membranas do lado da alimentação tende a zero. Estudos prévios já mostraram que quanto maior a turbulência, menor será a polarização, que é um efeito indesejado por reduzir a eficiência do processo.

Este trabalho tem por objetivo determinar a máxima corrente a ser utilizada na unidade sem que ocorra a polarização das membranas de troca iônica; bem como avaliar a influência das vazões de eletrólito, da solução diluída e da solução concentrada na eficiência do processo de eletrodiálise para a remoção do íon $\mathrm{Cr}_{2} \mathrm{O}_{7}{ }^{-2}$ de determinada solução. 


\section{MATERIAIS E MÉTODOS}

\subsection{Determinação da Densidade de Corrente Limite}

O método utilizado para determinar a densidade da corrente limite foi o desenvolvido por Cowan e Brown em 1959. Recomenda-se para maior eficiência do processo aplicar um valor máximo de $80 \%$ de $\mathrm{i}_{\text {lim }}$, o que garante estar na região ôhmica do processo.

Os testes foram realizados na unidade mostrada na Figura 2. Os tanques A, B e C são os reservatórios de eletrólito, solução diluída e solução concentrada, respectivamente. A fonte utilizada tem uma voltagem mínima de 0,00 e máxima de 60,00 V. Foram aplicados potenciais elétricos $(\mathrm{V})$ nas células eletrolíticas e medidos valores de corrente elétrica (I). $\mathrm{O}$ potencial foi aumentado em passos de $0,2 \mathrm{~V}$ e aguardou-se a estabilização para leitura de corrente; a vazão manteve-se constante em $20 \mathrm{~L} / \mathrm{h}$. Em seguida, foi feito o gráfico de V/I $(\mathrm{V} / \mathrm{A}=\mathbf{\prime} \Omega)$ por $1 / \mathrm{I}\left(\mathrm{A}^{-1}\right)$, como na Figura 3 , onde a inflexão da curva indica a $\mathrm{i}_{\text {lim }}$

Figura 2-Unidade experimental.

Figura 3-Curva de Cowan \& Brown, 1989.
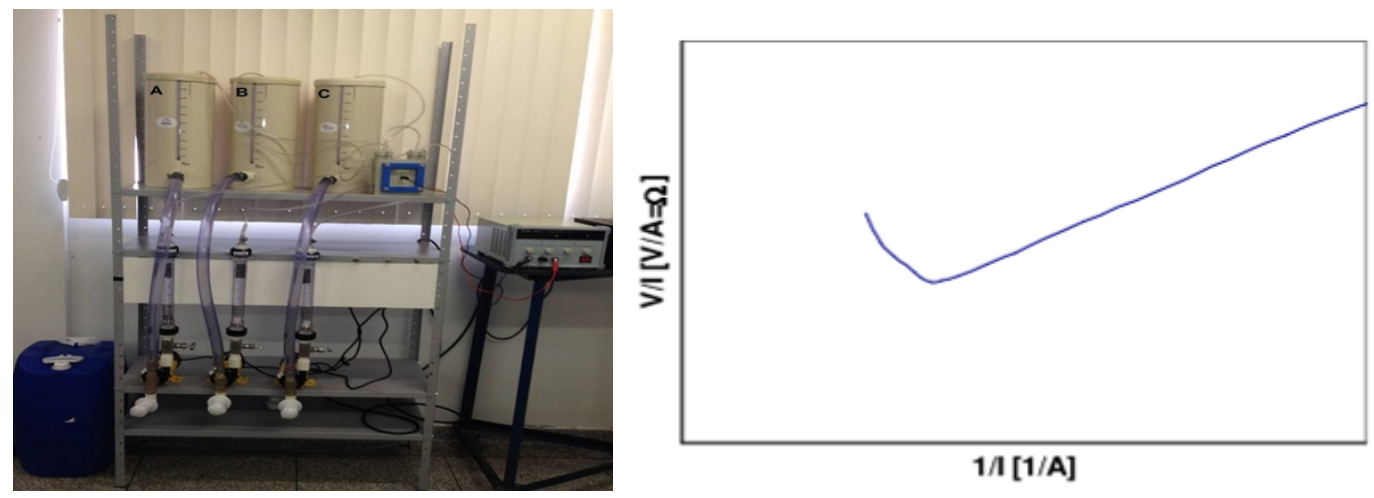

Soluções utilizadas: Em todos os testes realizados, as soluções diluídas eram compostas por dicromato de potássio $\left(\mathrm{K}_{2} \mathrm{Cr}_{2} \mathrm{O}_{7}\right)$, variando-se apenas as concentrações. Desejava-se a remoção do íon $\mathrm{Cr}_{2} \mathrm{O}_{7}^{-2}$ dessa para a solução concentrada, devendo o eletrólito atuar apenas como um "inerte" necessário para manutenção dos potenciais nos eletrodos. Para encontrar a massa de dicromato responsável por determinada concentração de cromo hexavalente, multiplicou-se a concentração desejada de cromo pelo fator 2,83 .

A Tabela 1 mostra as soluções utilizadas em cada teste, sendo o líquido utilizado para dissolução dos sólidos água destilada.

Tabela 1-Eletrólito, solução diluída e solução concentrada utilizada em cada teste.

\begin{tabular}{|c|c|c|c|c|}
\hline Teste & Eletrólito & Sol. Diluída & Sol. Concentrada & Volume \\
\hline 1 & $\mathrm{Na}_{2} \mathrm{SO}_{4} 0,25 \mathrm{M}$ & $\begin{array}{c}\mathrm{K}_{2} \mathrm{Cr}_{2} \mathrm{O}_{7}(150 \mathrm{mg} / \mathrm{L} \\
\left.\mathrm{Cr}^{6+}\right)\end{array}$ & Água destilada & $\begin{array}{l}2 \text { L de cada } \\
\text { solução }\end{array}$ \\
\hline 2 & $\mathrm{Na}_{2} \mathrm{SO}_{4} 0,25 \mathrm{M}$ & $\begin{array}{c}\mathrm{K}_{2} \mathrm{Cr}_{2} \mathrm{O}_{7}(150 \mathrm{mg} / \mathrm{L} \\
\left.\mathrm{Cr}^{6+}\right)\end{array}$ & $\begin{array}{c}\mathrm{K}_{2} \mathrm{Cr}_{2} \mathrm{O}_{7}(150 \mathrm{mg} / \mathrm{L} \\
\left.\mathrm{Cr}^{6+}\right)\end{array}$ & $\begin{array}{l}2 \mathrm{~L} \text { de cada } \\
\text { solução }\end{array}$ \\
\hline
\end{tabular}



3
$\mathrm{K}_{2} \mathrm{Cr}_{2} \mathrm{O}_{7}(150 \mathrm{mg} / \mathrm{L}$
$\mathrm{K}_{2} \mathrm{Cr}_{2} \mathrm{O}_{7}(150 \mathrm{mg} / \mathrm{L}$
$\mathrm{K}_{2} \mathrm{Cr}_{2} \mathrm{O}_{7}(150 \mathrm{mg} / \mathrm{L}$
2 L de cada $\mathrm{Cr}^{6+}$ $\mathrm{Cr}^{6+)}$ $\left.\mathrm{Cr}^{6+}\right)$ solução

\subsection{Avaliação das Vazões na Eficiência da Eletrodiálise}

Nos testes realizados, utilizou-se uma célula de eletrodiálise com dois compartimentos PCCell ED 64002 contendo dez membranas aniônicas (PC SA) e onze catiônicas (PC SK), sendo ambas do tipo ED 64-002-010.

O sistema experimental utilizado foi o mesmo mostrado pela Figura 2. Em todos os experimentos, as concentrações das soluções diluída e concentrada foram $100 \mathrm{mg} / \mathrm{L} \mathrm{Cr}$ (VI) e o eletrólito foi uma solução de $\mathrm{Na}_{2} \mathrm{SO}_{4} 0,25 \mathrm{M}$. A voltagem da fonte manteve-se constante em $16 \mathrm{~V}$ e a vazão do sistema variou conforme mostra Tabela 2.

Tabela 2-Vazão do eletrólito, solução diluída e solução concentrada em cada teste.

\begin{tabular}{cccc}
\hline Teste & Eletrólito $(\mathrm{L} / \mathrm{h})$ & Diluída $(\mathrm{L} / \mathrm{h})$ & Concentrada $(\mathrm{L} / \mathrm{h})$ \\
\hline 1 & 20 & 20 & 20 \\
2 & 20 & 40 & 40 \\
3 & 20 & 60 & 60 \\
4 & 40 & 40 & 40 \\
5 & 60 & 60 & 60 \\
\hline
\end{tabular}

As soluções diluída e concentrada continham água destilada e dicromato de potássio $\left(\mathrm{K}_{2} \mathrm{Cr}_{2} \mathrm{O}_{7}\right)$ na quantidade adequada para atingir a concentrações desejada de cromo hexavalente $(100 \mathrm{mg} / \mathrm{L})$, ou seja, para encontrar a massa de $\mathrm{K}_{2} \mathrm{Cr}_{2} \mathrm{O}_{7}$ necessária multiplicou-se estas concentrações pelo fator 2,83 .

Para a determinação da concentração das espécies iônicas na solução diluída, foram coletadas alíquotas em intervalos de 5 em 5 minutos por aproximadamente uma hora para cada vazão analisada.

Métodos analíticos: As amostras coletadas foram quantificadas em relação à concentração de cromo hexavalente pelo método colorimétrico com difenilcarbazida conforme o Standard Methods for the Examination of Waterand Wastewater- APHA (2005).

\section{RESULTADOS}

\subsection{Determinação da Densidade de Corrente Limite}

Comparando as Figuras 4, 5 e 6 com a Figura 3, pode-se observar que a curva que apresentou um comportamento qualitativo mais próximo do reportado na literatura foi a do teste 2, ou seja, onde a solução diluída e concentrada tinham a mesma concentração de cromo hexavalente $(150 \mathrm{mg} / \mathrm{L} \mathrm{Cr})$ e o eletrólito era solução de $\mathrm{Na}_{2} \mathrm{SO}_{4} 0,25 \mathrm{M}$. Isso possivelmente indica que a solução concentrada e o eletrólito influenciam na recepção dos íons da solução diluída e na eficiência do eletrodo, respectivamente. Pela Figura 6 verificou-se que quando o eletrólito é igual à solução diluída e concentrada a curva apresenta mais inflexões, o que dificulta a estimativa da densidade da corrente limite. 


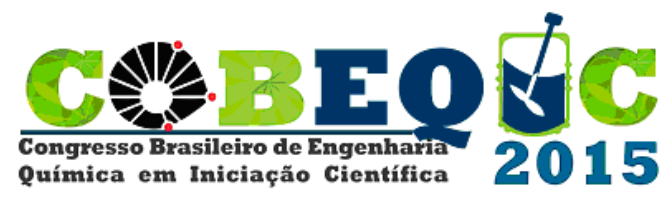

Figura 4-Corrente limite-teste 1.

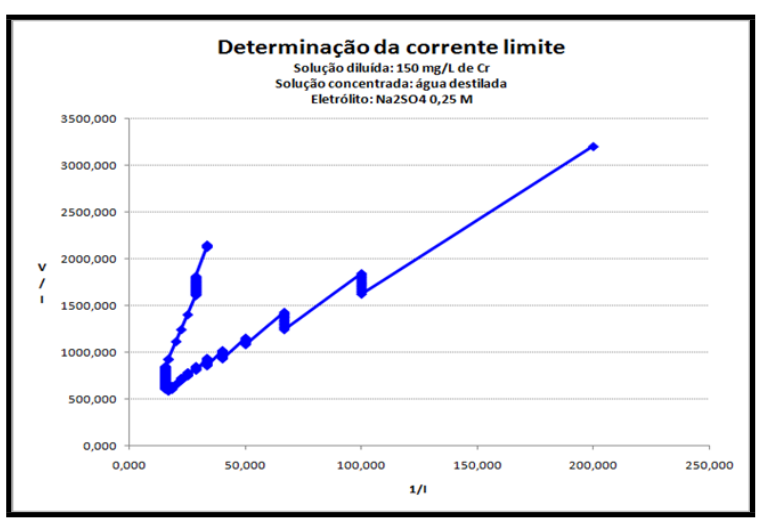

Figura 6-Corrente limite-teste 3.

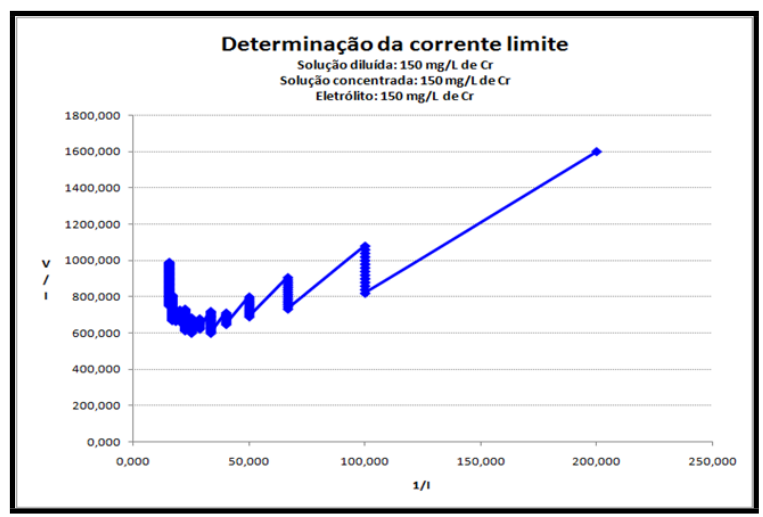

XI Congresso Brasileiro de Engenharia Química em Iniciação Científica Unicamp - Campinas - SP 19 a 22 de julho de 2015

Figura 5-Corrente limite-teste 2.

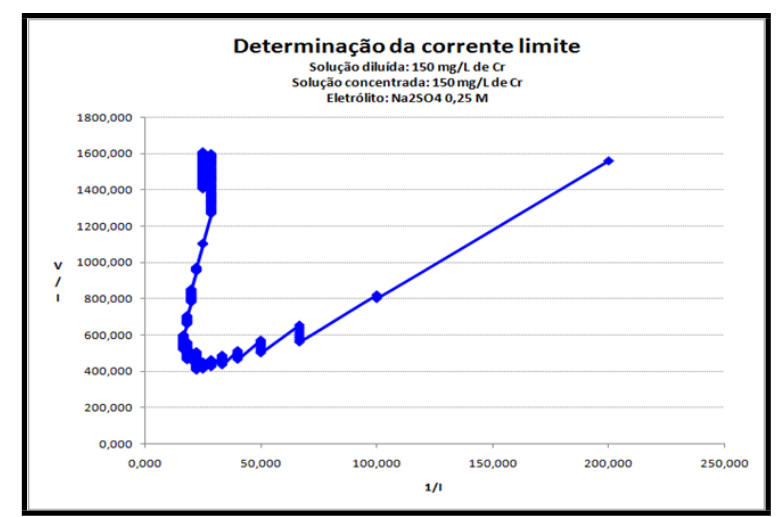

\subsection{Avaliação das Vazões na Eficiência da Eletrodiálise}

A Figura 7 traz a variação da concentração de cromo (VI) com o tempo para todas as vazões estudadas. Pode-se observar que as vazões 20-60-60, 40-40-40 e 60-60-60 L/h conseguem remover o cromo da solução diluída em um intervalo de tempo menor que as vazões $20-20-20$ e $20-40-40 \mathrm{~L} / \mathrm{h}$.

De acordo com o Manual de Manutenção e Operação da PCCell ED 640 02, as vazões das soluções diluída e concentrada devem variar entre 40 e $80 \mathrm{~L} / \mathrm{h}$, sendo que valores inferiores ou superiores a esses comprovadamente reduzem a vida útil e a eficiência das membranas. Em relação à vazão do eletrólito, a recomendação é que sua vazão não seja maior que das soluções diluída e concentrada.

As melhores vazões para operação da unidade é 20-60-60 e 60-60-60 L/h. Pode-se observar que nessas condições ambas as curvas apresentam um comportamento decrescente homogêneo e praticamente se sobrepõem uma à outra, podendo ser os desvios existentes entre as mesmas associados ao próprio experimento laboratorial. Nessas condições tem-se a melhor remoção de cromo da solução diluída e uma margem de segurança de $25 \%$ a menos em 
relação ao limite de vazão da solução diluída e concentrada informado pelo fabricante da célula de eletrodiálise

Figura 7-Variação da concentração de $\mathrm{Cr}$ (VI) com o tempo para todas as vazões estudadas.

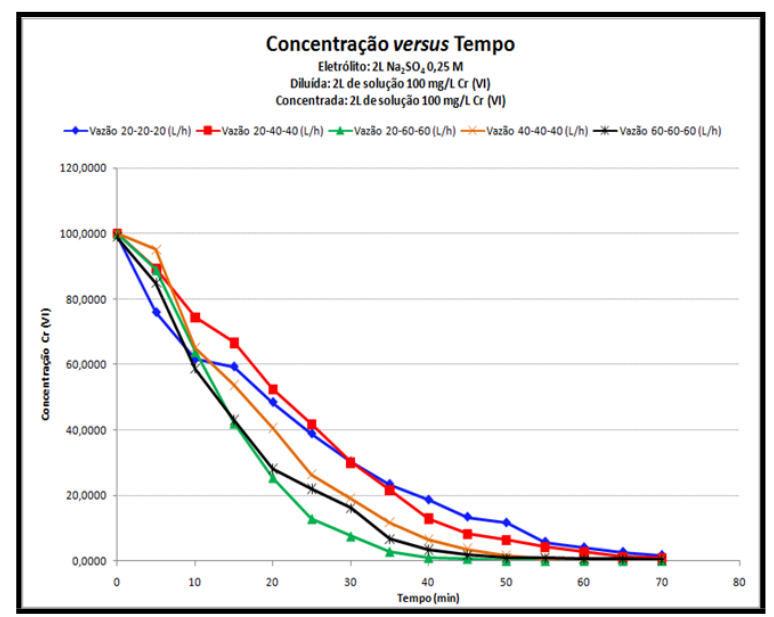

Optou-se por trabalhar com um tempo de aproximadamente 50 minutos de operação para atingir o limite máximo de lançamento de $\mathrm{Cr}$ (VI) e $\mathrm{Cr}$ (III) em rios, mas em condições não extremas, o que garante uma durabilidade maior das membranas da célula eletrolítica, já que essas são importadas e apresentam alto custo e longo tempo de espera para aquisição. No Brasil, segundo a Resolução CONAMA n $\mathrm{n}^{\circ} 397$ de 2005, os limites máximos de lançamento de $\mathrm{Cr}$ (VI) e $\mathrm{Cr}$ (III) em rios são de 0,1 e $1 \mathrm{mg} / \mathrm{L}$, respectivamente.

\section{CONCLUSÕES}

- A corrente máxima a que o sistema pode ser submetido sem que ocorra a polarização das membranas de troca iônica é $0,03 \mathrm{~A}$, e uma voltagem de aproximadamente $16 \mathrm{~V}$.

- Maiores vazões de eletrólito, solução diluída e concentrada apresentam um menor tempo para remoção de Cr (VI) e, consequentemente, atingem os limites legais para lançamento dos efluentes nos rios mais rápido. Para uma margem de segurança de $25 \%$ a menos em relação ao limite estabelecido pelo fabricante da célula eletrolítica, as melhores vazões foram 20-60-60 e 60-60-60 L/h

\section{REFERENCIAS}

AMORIM, L.V; GOMES, C. M.; SILVA, F. L. H.; FRANÇA, K. B.; LIRA, H. L.; FERREIRA, H. C. Uso da eletrodiálise na eliminação de $\mathrm{Ca} 2+$ e $\mathrm{Mg} 2+$ e sua influência na reologia de dispersões de argilas bentoníticas da Paraíba. Março 2005.

APHA, Standard Methods for the examination of water \& wastewater, 3500-Cr B. Colorimetric Method, Washington, D.C, p.3-66, 2005

CONAMA, Resolução $N^{o} 357 / 2005$, Ministério do meio ambiente, capítulo 4, artículo 34, \&5. In: www.mma.gov.br/conama, acessado em 12/02/2015.

COWAN, D.A.; BROWN,J.H. Effect of turbulence on limiting current inelectrodialysis cells. Industrial Engineering Chemistry Research, [S.1], v.51, p.1445, 1959.

GALUCHI, T.P. D. Dissertação de mestrado "Montagem e Caracterização de unidade de eletrodiálise em escala de laboratório para tratamento de soluções salinas". São PauloSetembro, 2010. 